\title{
RECHERCHES SUR LE CYCLE ÉVOLUTIF DE TRYPANOSOMA CRUZI CHAGAS \\ A PROPOS DE L'INFESTATION PÉRITONÉALE EXCLUSIVE CHEZ LA SOURIS
}

\author{
Par H. GALLIARD
}

\section{Introduction}

Nous avons publié autrefois dans ces Annales (1929 et 1930) deux courtes notes préliminaires concernant la localisation péritonéale de Trypanosoma cruzi au cours d'infections chez la souris. Les années ont passé. Mais, récemment, des travaux nouveaux ont paru sur le cycle de ce trypanosome, et de plus l'obtention de cultures sur embryon de poulet a fait faire de nouveaux progrès. Ceci nous a incité à reprendre l'étude d'un matériel très important que nous avions conservé, à donner plus de détails sur les faits observés et à confronter nos conclusions avec celles des différents auteurs qui se sont intéressés à la question.

Nous aurons uniquement en vue ici l'évolution chez l'hôte vertébré. L'évolution en culture artificielle ou chez le réduvidé est en effet complètement différénte et ne peut apporter aucun renseignement utile pour l'interprétation des faits.

\section{Matériel et méthodes}

La souche de T. cruzi utilisée avait été rapportée par le Professeur E. Brumpt, de Montevideo (Uruguay), sur Triatoma rubrovaria. Nous avions constaté que la souche entretenue sur souris perdait progressivement sa virulence par passage de sang de souris à souris ou avec les déjections de réduves. Cette virulence ne pouvait être maintenue qu'avec l'inoculation de cultures. Dans ce cas, les souris mouraient dans un état de cachexie extrême, avec de rares trypanosomes dans le sang périphérique. Parfois, les trypanosomes étaient introuvables dans le sang. C'est en recherchant l'évolution

Ann. de Panasitologie, т. XXVII, No $1-2-3 .-1952$. 
des formes de culture injectées dans le péritoine que nous avions constaté dans l'exsudat la présence de trypanosomes en nombre incomptable quelques jours après l'inoculation.

Il ne s'agissait pas d'une culture in situ, car le même phénomène s'est reproduit après inoculation sous la peau. Nous n'avons pas vu la reproduction se faire dans la séreuse péritonéale. Rien n'a été observé dans les coupes à ce sujet, et les formes trouvées dans les frottis de péritoine pouvaient provenir des tissus sous-cutanés ou de la rupture d'un kyste musculaire voisin.

Cependant, la reproduction se faisait au voisinage de la séreuse : les formes évolutives étaient surtout nombreuses dans les muscles abdominaux, parfois dans ceux des cuisses, du dos, du diaphragme, dans le tissu cellulaire, les cellules adipeuses, les fibroblastes, les histiocytes, les macrophages, les cellules endothéliales. Elles étaient souvent absentes et toujours très rares dans le cœur. Les trypanosomes étaient non seulement en nombre considérable dans le péritoine, à la période d'état, mais aussi dans l'œdème sous-cutané et parfois dans le péricarde.

Dans une expérience, sur sept souris sacrifiées journellement après inoculation de culture sous la peau, on trouvait des trypanosomes dans le péritoine dès le $2^{\circ}$ jour et à partir du $8^{\circ}$ jour seulement dans le sang.

Les souris mouraient entre le $14^{\circ}$ et le $23^{\circ}$ jour avec des trypanosomes incomptables dans le péritoine et introuvables ou très rares dans le sang.

Quand du sang infectieux était injecté sous la peau ou dans le péritoine, la mort s'est produite du $14^{\circ}$ au $21^{\circ}$ jour, et les trypanosomes étaient introuvables ou rares dans le sang, suivant le cas. Dans un cas, une souris a guéri vers le $58^{\circ}$ jour.

Avec l'exsudat péritonéal, les souris mouraient du $16^{\circ}$ au $38^{\circ}$ jour. Les trypanosomes étaient absents ou très rares dans le sang. La durée de l'évolution était donc variable et fonction de la dose inoculée.

Les cultures se sont montrées un peu plus virulentes. La voie d'inoculation avait une influence variable. La souris 1.472 , inoculée dans le péritoine avec du sang, est morte le $58^{\circ}$ jour, sans parasites dans le sang, ni dans le péritoine. La souris 1.473 , inoculée sous la peau avec du sang, a présenté une infection considérable de l'exsudat péritonéal et sous-cutané, et légère du sang. Elle est morte le $26^{\circ}$ jour. Mais il s'agissait d'un seul cas. L'absence ou la présence de trypanosomes dans le sang n'était pas non plus conditionnée par un facteur appréciable. Il arrivait que les parasites soient plus nombreux dans le sang du cœur que dans le sang péri- 
phérique. Les formes Leishmania étaient souvent absentes et toujours très rares dans le muscle cardiaque.

Avec les déjections infectieuses, la mort s'est produite au bout de 15 à 27 jours ; dans la plupart des cas, entre 15 et 22 jours.

L'inoculation du virus aux souris splénectomisées n'a pas semblé augmenter la virulence. La mort s'est produite entre le $9^{\circ}$ et le $34^{\circ}$ jour. Il n'y a pas eu de différences notables entre les cas où la splénectomie a été effectuée avant ou après l'inoculation.

Enfin, l'association avec Borrelia duttoni n'a pas exalté la virulence de $T$. cruzi. L'infection extraordinaire de la souris 1.441 n'a constitué qu'un fait isolé, bien que les autres souris soient également mortes de leur infection.

Le rat n'a présenté qu'une infection péritonéale légère et transitoire et, au contraire, une infection sanguine classique.

Les examens ont été faits soit à l'état frais, soit sur frottis colorés au May-Grünwald-Giemsa, soit sur coupes. La fixation a été faite par l'acide osmique ou par simple dessiccation. Les trypanosomes sont beaucoup moins labiles dans la sérosité péritonéale que dans le sang, et se prêtent plus facilement à l'étalement. L'absence d'hématies facilite la fixation et la coloration des gouttes épaisses ou plutôt des étalements épais. Les pièces ont été fixées soit au Dubosc-Brazil, soit au Zenker. Les coupes ont été colorées au Giemsa, à l'hémalun-éosine et à l'hématoxyline ferrique.

D'autres souches de $T$. cruzi ont été utilisées: virus Uruguay, conservé sur Triatoma rubrovaria; virus Cabral, sur T. chagasi ; virus Chagas, sur T. megista. Les souches se sont comportées normalement, c'est-à-dire que les formes Leishmania ont proliféré dans le cœur, et les formes métacycliques se trouvaient exclusivement dans le sang périphérique.

L'intensité de l'infestation obtenue chez les souris jeunes ou âgées, la massivité du parasitisme, aussi bien dans le péritoine et la sérosité sous-cutanée que dans les muscles adjacents et le tissu conjonctif sous forme évolutive, nous ont fait penser à reétudier les différentes formes du cycle de $T$. cruzi. Etant donné la multiplication anarchique du parasite, on pouvait avoir la chance de saisir son évolution aux stades les plus variés. Nous n'insisterons pas sur les lésions produites dans les tissus. Elles étaient cependant considérables, et dans la paroi abdominale se produisaient parfois une disparition presque complète des fibres musculaires et leur remplacement par des kystes parasitaires intacts ou envahis par les leucocytes. Nous avons déjà dit que l'infection était localisée dans les muscles de la région abdominale et lombaire, et, fréquemment, il n'a pu être retrouvé aucun parasite dans le cœur. Existe-t-il une

Ans. de Parastrologie, T. XXVII, $\mathrm{N}^{\circ} 1-2-3 .-1952$. 
relation de cause à effet entre cette localisation, l'intensité de l'infection péritonéale et la rareté, parfois l'absence complète, de parasites dans le sang ? Nous ne pourrions l'affirmer.

\section{Les formes évolutives intra-tissulaires}

Historique. - Les différents auteurs qui ont représenté le cycle intratissulaire ou intracellulaire de $T$. cruzi (Brumpt, Wenyon, Reina Guerra, Chagas, Vianna, Mayer et da Rocha Lima, Nino, Kofoid et Donat) ont souvent bien figuré la double forme rencontrée dans les frottis de muscles généralement du cœur, que Mayer et da Rocha Lima, Elkeles ont appelée forme de transition. Elkeles les a trouvées dans des cultures. Plus récemment, Sherwin Wood a appelé développement direct la formation du trypanosome par allongement de la forme Leishmania en Leptomonas et migration du blépharoplaste à la partie postérieure du corps, et développement indirect celui qui se produit à partir de formes sphériques, entourées de leur flagelle et qui n'ont plus, d'après cet auteur, qu'à se déplier en $\mathrm{V}$ pour donner la forme Trypanosoma.

Tels sont les faits d'observation. Il semble cependant que l'on se soit un peu trop hâté pour relier les différentes formes entre elles, car, dans un frottis de muscles, par exemple, rien ne vous prouve qu'une forme peut dériver d'une autre. Elkeles avait suivi à frais dans les cultures le processus de « rétrogression ». Malheureusement, la plupart des formes trouvées en culture ne se rencontrent jamais chez le vertébré.

Par ailleurs, les résultats obtenus par culture sur embryon de poulet ne nous renseignent pas de façon définitive. On y trouve en effet les mêmes formes de culture qu'en milieu artificiel. Cependant, le développement intracellulaire a pu être observé (Kofoid et al., 1937 ; Romanã et Meyer, 1942 ; Hawking, 1946 ; Soto, Loretti et Rispoli, 1950). Meyer et Xavier de Oliveira, depuis 1941, ont pu voir le parasite se transformer de Trypanosoma en Crithidia, puis en Leishmania, et inversement « la multiplication du parasite sous forme Crithidia et Leishmania par division binaire », pour redonner ensuite la forme Trypanosoma.

Ce genre d'évolution constitue donc un compromis entre l'évolution en milieu artificiel et le milieu vivant. Il est pourtant difficile de conclure trop absolument de l'embryon de poulet au mammifère. Par ailleurs, ces auteurs ont vu des formes Trypanosoma larges se former dans les cellules qui finissent par ne plus contenir, quelque temps après, que des formes grêles. Cependant, ils n'ont jamais pu 
suivre le passage de l'une à l'autre. Et l'inconvénient de la méthode est que tout le cycle se passe dans une cellule qui éclate lorsqu'elle est trop pleine, et met en liberté des formes encore immatures.

Romanã et Meyer (1942) ont vu les trypanosomes pénétrer activement dans les cellules, alors que les Crithidia sont absorbées par elles, puis s'immobiliser. Vingt heures après la pénétration, la membrane ondulante disparait, le flagelle se raccourcit, le corps devient globuleux et prend une forme semblable à Crithidia. Quelques heures après, la Leishmania est formée. Cette transformation s'est accompagnée d'une migration du blépharoplaste, qui, de corpuscule arrondi, est devenu bâtonnet, vers l'extrémité antérieure. A partir de ce moment, il devient difficile de suivre l'évolution des flagellés qui ont la même réfringence que le cytoplasme des cellules.

On assiste ensuite à la retransformation en trypanosomes. Cependant, les cellules parasitées éclatent de façon précoce et libèrent des formes immatures. Dans ce cas, les Leishmania ne peuvent continuer leur développement et dégénèrent. Cependant, les auteurs voient deux types de «trypanosomes adultes semblables à ceux que l'on trouve dans le sang circulant des vertébrés 》: des formes minces à déplacement « ondulatoire en ligne droite 》 et des formes larges se mouvant sur place. Cependant, il ne leur est pas possible, d'après leurs recherches, de confirmer la thèse classique et d'affirmer qu'une forme dérive de l'autre. Ces auteurs ont vu aussi que les formes Crithidia et trypanosome, provenant soit de culture en milieu artificiel, soit de culture de tissu, prennent, après avoir pénétré dans les cellules ou dans le milieu externe, l'aspect arrondi, enroulé, et se transforment en Leishmania. A la fin de l'évolution, on observe aussi des formes Leishmania qui se transforment apparemment en parasites adultes par un déroulement du flagelle sans migration du blépharoplaste, et, par conséquent, sans formation intermédiaire de Crithidia.

On verrait done dans ce genre de reproduction, ou plutôt de culture, chez l'embryon, les deux cycles de transition entre la forme Leishmania et la forme Trypanosoma, supposés par certains auteurs chez le mammifère.

Il semble cependant que l'existence de deux modes de formation des trypanosomes est une chose absolument anormale, à moins que l'on admette à priori un processus de sexualité dont l'existence n’a jamais été prouvée.

Nous insistons sur le fait également que l'on a établi un peu trop facilement une filiation entre les différentes formes trouvées dans les frottis par apposition ou dilacération de tissus, sous prétexte qu'elles étaient voisines sur la préparation. Or, ce mélange de for- 
mes contraste avec le fait que l'unanimité des auteurs a admis que dans chaque kyste intramusculaire ou autre, tous les parasites étaient au même stade, et que la transformation dans le stade suivant se faisait simultanément pour toutes les formes. C'est ce que l'on constate en effet dans les coupes. Cependant, les différents auteurs n'ont pas été frappés du fait que l'on rencontre dans un kyste musculaire donné des formes absolument définies, mais que les étalements, au contraire, montrent une extraordinaire variété de formes, dont on a établi la dépendance de façon tout à fait arbitraire. Et l'on ne s'est pas préoccupé de savoir si les formes trouvées dans les frottis provenaient des kystes ou des tissus voisins.

Formes tissulaires dans le cas particulier de nos expériences. Nous avons eu la bonne fortune de pouvoir obtenir des infections particulièrement importantes, mais étroitement localisées au pourtour de la cavité abdominale, parfois de la cavité thoracique, et dans les membres.

Malgré l'intensité de l'infection, nous n'avons jamais constaté un mélange de formes dans le même kyste. C'étaient d'une part des Leishmania et d'autre part des formes métacycliques longues et grêles. Moins fréquemment, sauf chez certains animaux, on trouvait des formes allongées du type Leptomonas, avec le blépharoplaste situé latéralement par rapport au noyau, comme dans la figure $7, \mathrm{~B}$.

Nous n'avions jamais vu en coupe, dans les kystes des muscles, des formes sphériques (fig. 2, C), si nombreuses cependant dans les frottis. Elles eussent été cependant aisées à reconnaître et à distinguer des formes Leishmania grâce à leur blépharoplaste punctiforme. Cette absence totale nous avait paru étrange, et nous avions pensé que c'était des formes libres trouvées dans les mailles du tissu conjonctif plus ou moins œedémateux qui sépare les fibres musculaires. Notre hypothèse fut confirmée lorsque nous les avons trouvées, dans un cas surtout (1.441), dans la sérosité sous-cutanée en grande abondance. Ces formes retirées par ponction avaient été examinées vivantes, puis après fixation par dessiccation et coloration au Giemsa, et enfin dans des coupes de la région intéressée. A l'état frais (fig. 7), elles étaient toutes mobiles et avaient l'aspect de trypanosomes trapus. En coupe, l'aspect était le même : trypanosomes courts et trapus pullulant dans l'exsudat sous-cutané. Après fixation et coloration, au contraire, elles prenaient l'aspect arrondi représenté par les différents auteurs (cycle indirect de S. Wood).

L'habitat extracellulaire de ces formes a été confirmé par l'examen de coupes d'autres tissus. En certains points, les faisceaux 

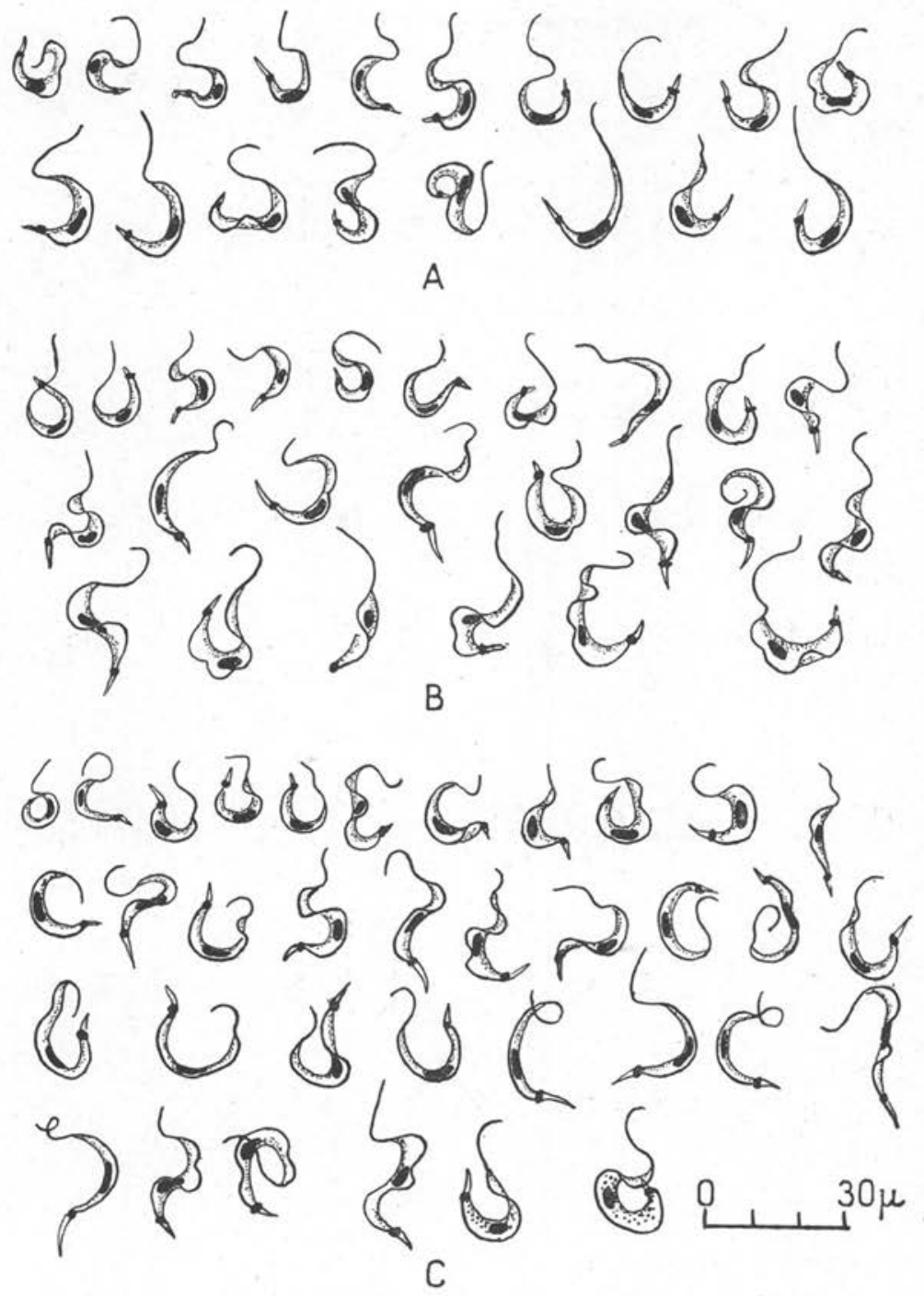

Fic. 1. - Souris 1.359. A, formes de l'exsudat péritonéal $4^{\mathrm{e}}$ jour ; $\mathrm{B}, 5^{\mathrm{e}}$ jour ; C, $8^{\mathrm{e}}$ jour.

musculaires étaient disséqués par l'œdème, dans lequel on les trouvait en extrême abondance. Mais dans les muscles, au voisinage immédiat, on trouvait de très nombreux kystes à Leishmania ou à trypanosomes métacycliques allongés.

Ainsi, nous ne pouvions penser que ces formes libres trapues, 


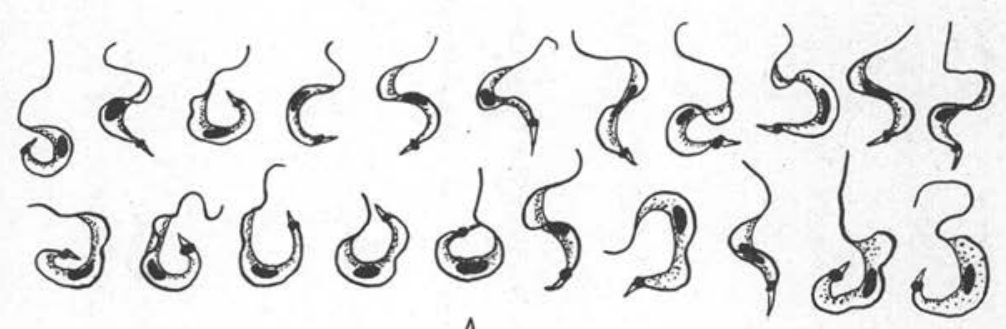

A
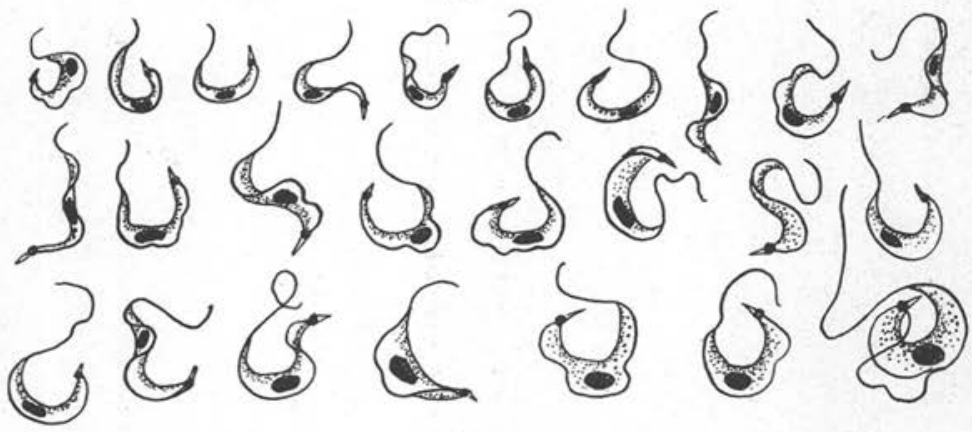

B

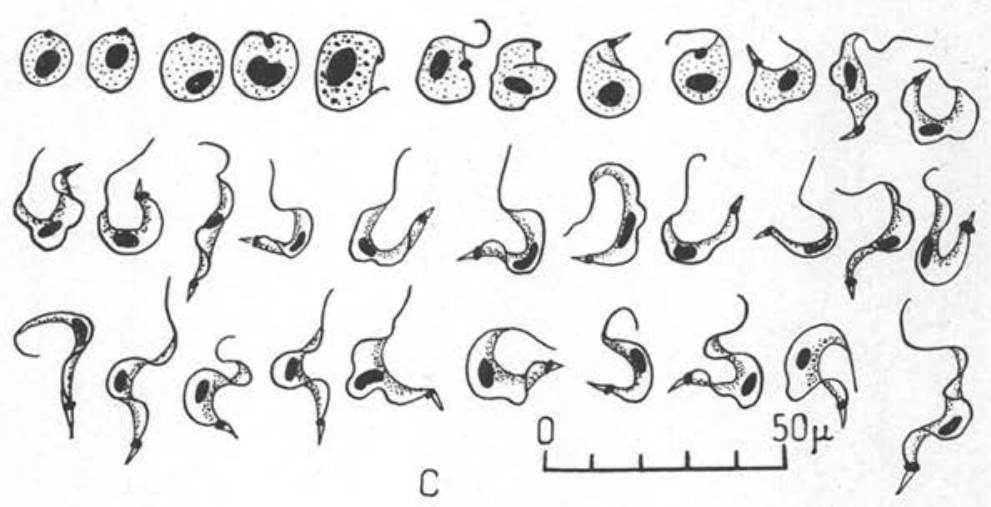

Fig. 2. - Souris 1.359. A, $13^{\mathrm{e}}$ jour ; B, $14^{\circ}$ jour ; C, frottis de muscle et sang cardiaques. Dans toutes les figures de ce travail, les formes ont été représentées dans l'ordre de la morphologie et des dimensions sans préjuger de la filiation entre elles.

prenant l'aspect sphérique après dessiccation, puissent provenir de ces formes allongées et grêles vues en coupe dans les kystes musculaires.

Mais nous avons constaté que les macrophages, les cellules réticulaires ou endothéliales des tissus qui baignaient dans l'exsudat 

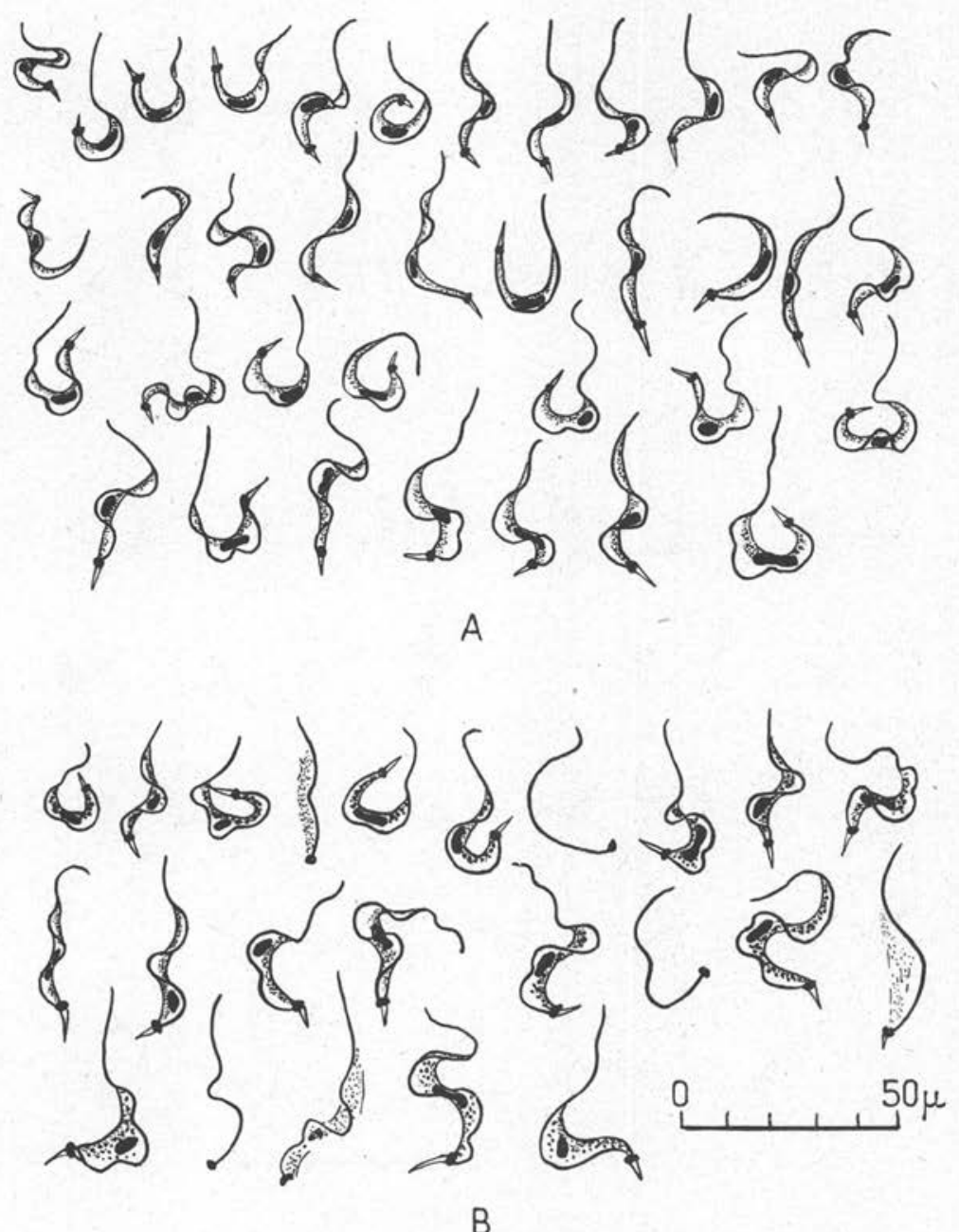

Fıt. 3. - Souris 1.379. Deux préparations du même exsudat péritonéal au $10^{\circ}$ jour pour montrer l'effet du mode d'étalement. A, étalement épais ; B, frottis mince. Les différences morphologiques ne portent en réalité que sur la longueur. La fragilité existe chez les formes petites aussi bien que les grandes.

étaient remplies de formes diverses : d'abord des formes Leishmania. Mais ces Leishmania étaient de taille plus petite (fig. 10, d) que celle des formes musculaires, et, de plus, on trouvait des formes arrondies ou allongées, mais à blépharoplaste punctiforme (fig. 10,c) comme les formes libres trouvées dans la sérosité. Ces formes arron- 

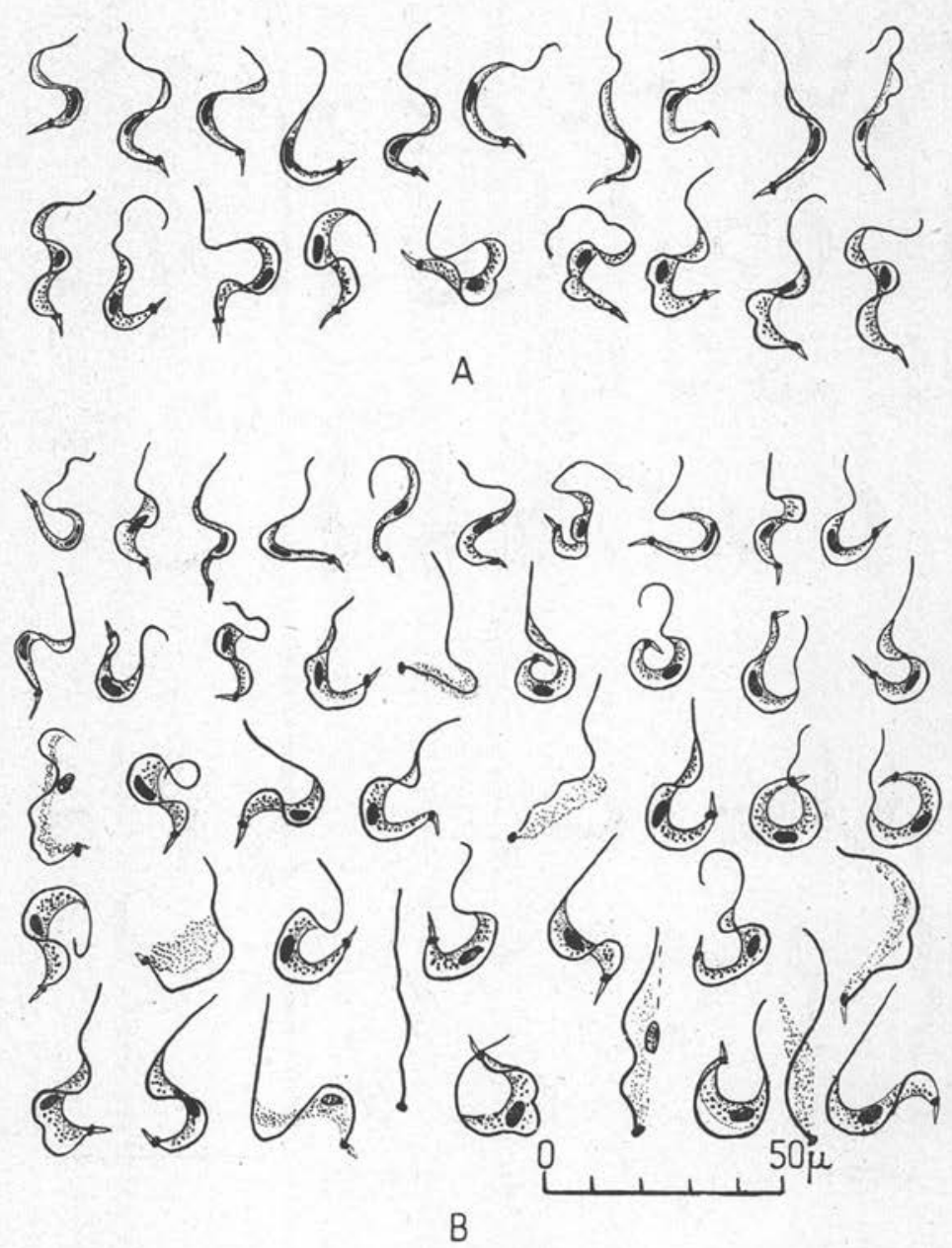

FIG. 4. - Souris 1.379. A, formes péritonéales au $23^{e}$ jour : étalement épais ; B, le même jour, frottis mince.

dies intracellulaires semblaient avoir un rapport étroit avec les trypanosomes libres dans les mailles du tissu conjonctif.

On conçoit done que si l'on fait un frottis par apposition du tissu ou avec le produit de dilacération, on obtienne un mélange de formes le plus extraordinaire.

Comment peut-on concevoir la filiation de ces différentes formes? Nous repoussons à priori, comme nous l'avons dit, toute idée d'un double cycle évolutif chez les vertébrés, comme contraire aux lois 


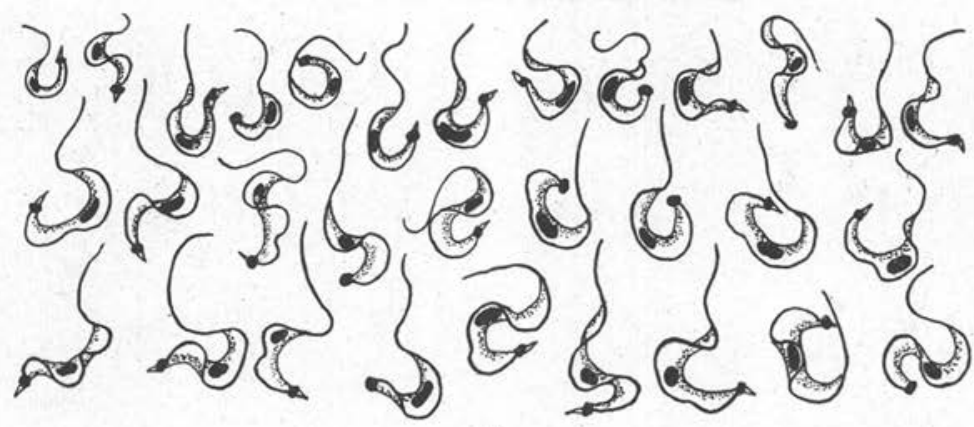

A

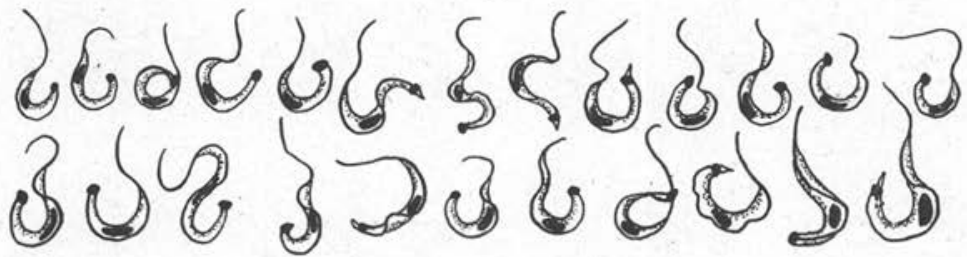

B

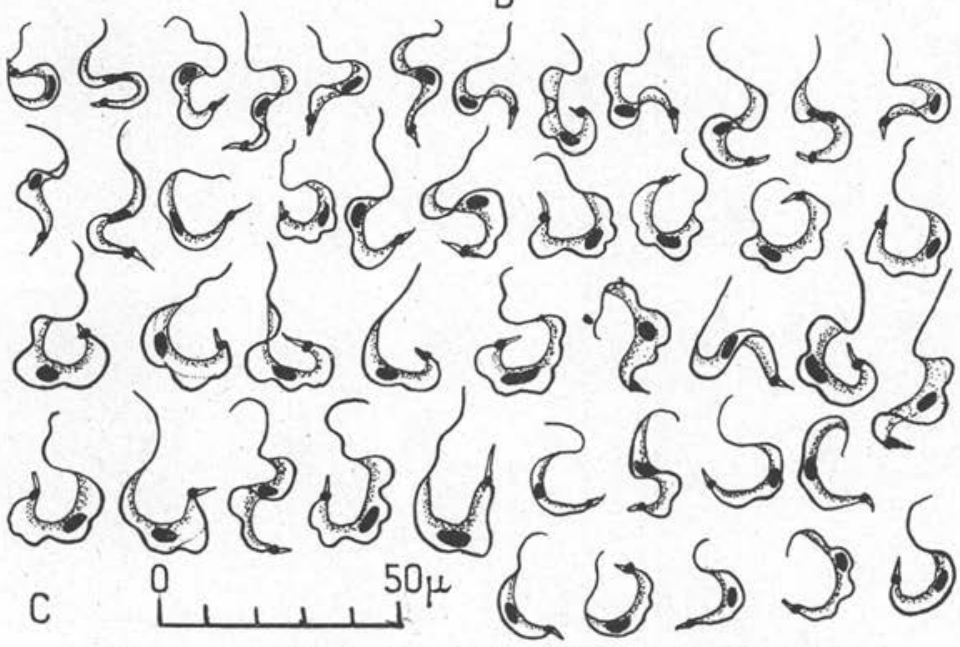

FIG. 5. - Souris $1.388,17^{\mathrm{e}}$ jour. A, exsudat sous-cutané ;

$\mathrm{B}$, sang périphérique; $\mathrm{C}$, péritoine.

de l'évolution des trypanosomes. Rappelons que nous voyons dans une même coupe, parfois le même champ microscopique : des formes Leishmania et des trypanosomes grêles et allongés dans les kystes musculaires; des formes Leishmania plus petites, mais à blépharoplaste normal, et des formes également rondes à blépharo- 

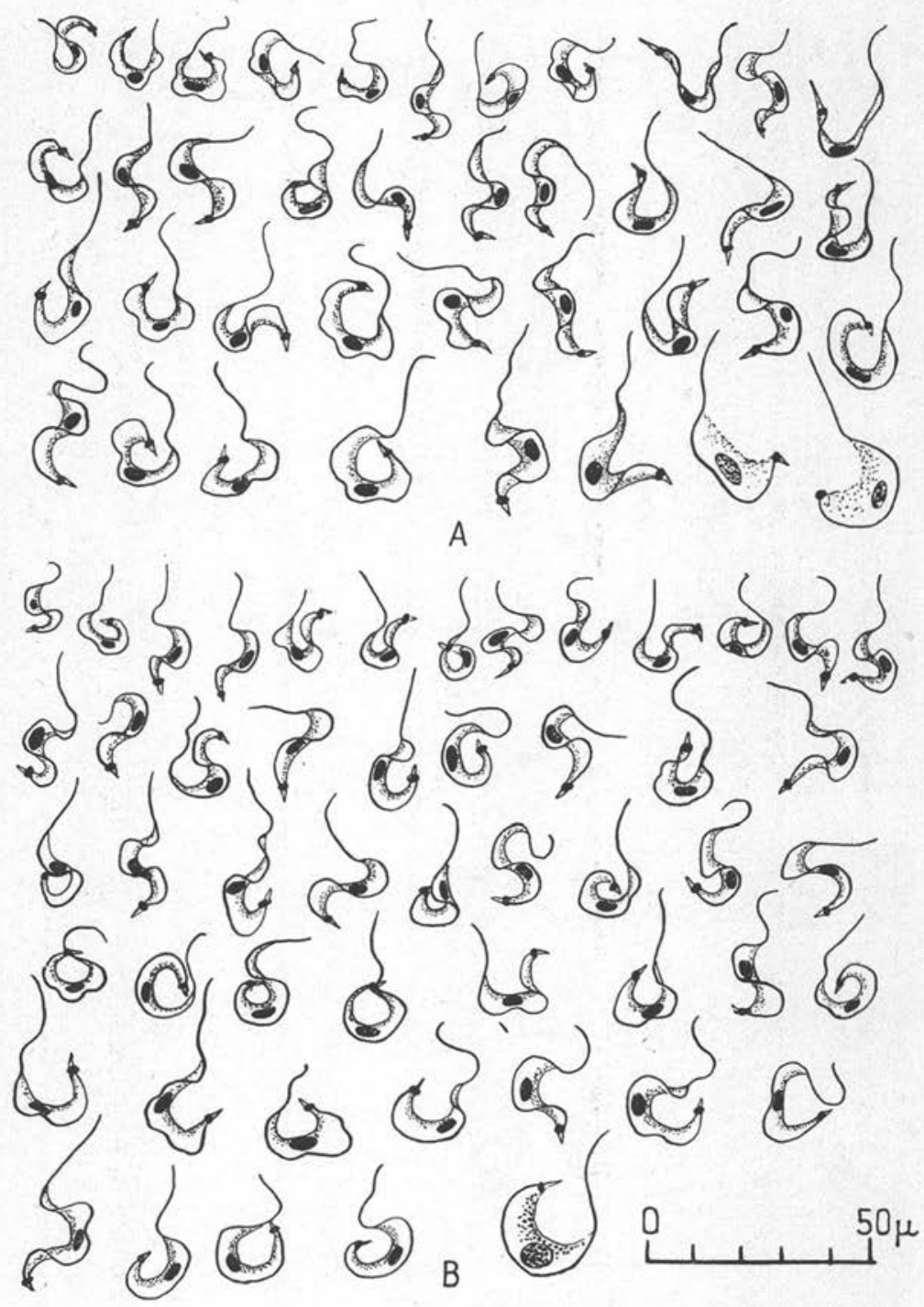

FIG. 6. - Souris 1.441. Exsudat péritonéal. $A, 12^{\mathrm{e}}$ jour ; $\mathrm{B}, 29^{\mathrm{e}}$ jour.

plaste punctiforme dans les cellules réticulaires et endothéliales ; et enfin des trypanosomes trapus, libres dans l'exsudat sous-cutané ou interfasciculaire. D'autre part, ces formes trapues prennent l'aspect arrondi dans un frottis desséché. Il y a donc une analogie cer- 


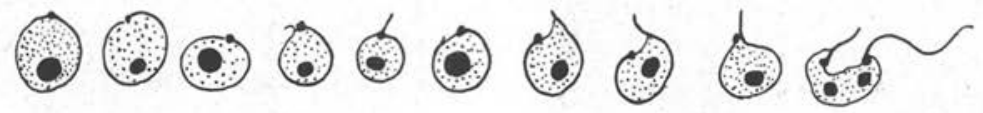

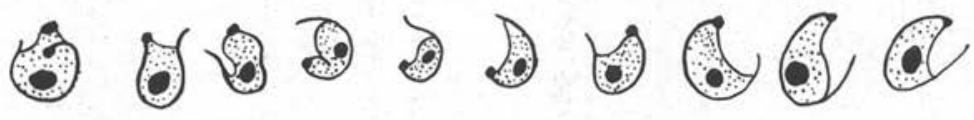

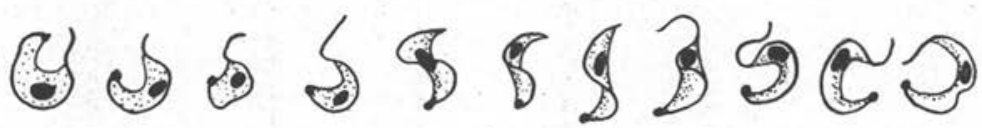
A

(1) (1) (1) (1)

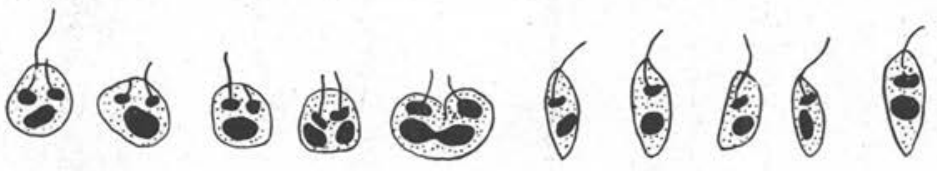

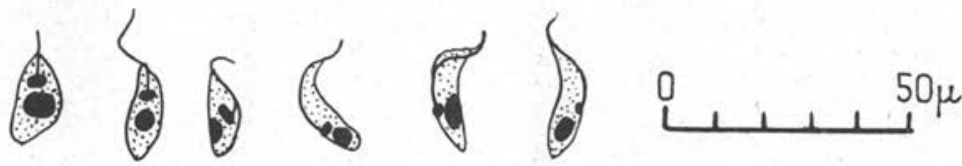

B

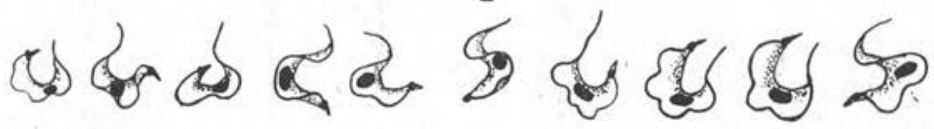

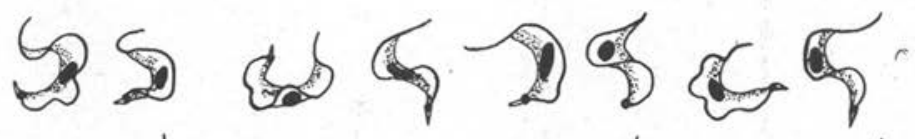

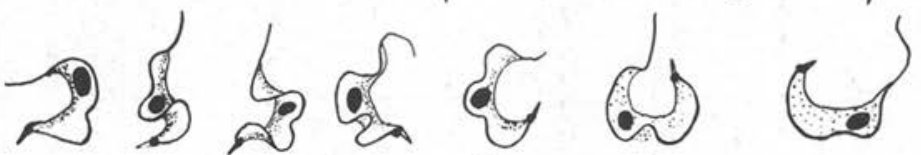

C

Fig. 7. - Souris 1.441, 30 jour. A, exsudat sous-cutané ; $\mathrm{B}$, frottis du muscle cardiaque; $\mathrm{C}$, goutte épaisse de sang périphérique.

taine entre ces formes libres et les formes arrondies qui se trouvent dans les histiocytes.

Une première hypothèse consisterait à admettre une influence purement mécanique. Le cytoplasme des cellules étant inextensible, les formes Leishmania ne pourraient se développer entièrement et 
atteindre leur taille normale, et donneraient prématurément des formes trypanosomes arrondies (cycle indirect de S. Wood). Dans les muscles, au contraire, les kystes seraient indéfiniment extensibles et le développement normal par l'intermédiaire des formes

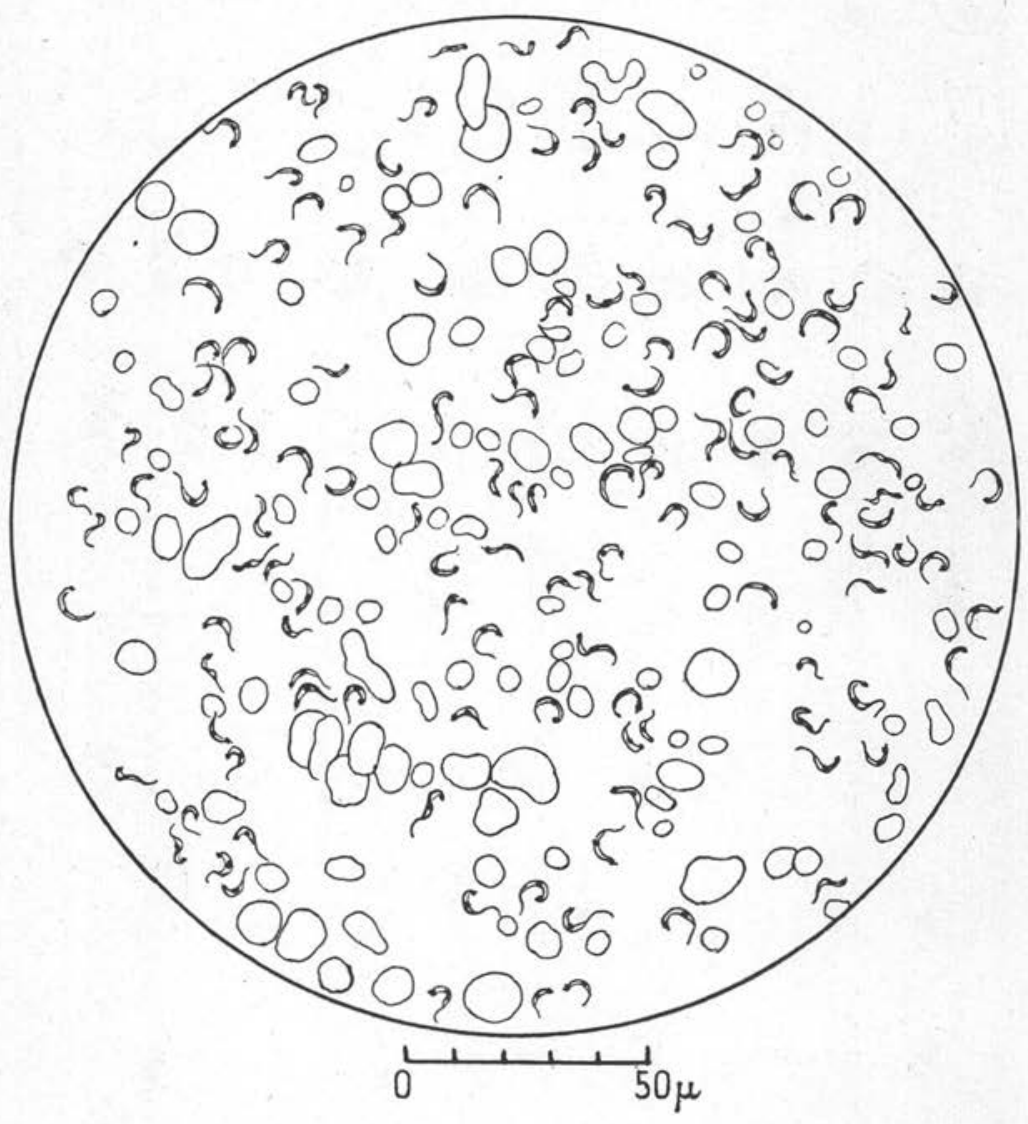

FIG. 8. - Souris 1.584. Trypanosomes dans l'exsudat péritonéal, le $16^{\circ}$ jour (May-Grünwald-Giemsa). On a figuré les noyaux des cellules blanches.

Leptomonas ou Crithidia, car, qu'on le veuille ou non, il arrive fatalement un moment où, le blépharoplaste émigrant vers l'extrémité postérieure du corps, le flagellé prend l'aspect de Crithidia, à moins que l'on ne trouve une autre dénomination.

Cependant, on n'a jamais expliqué comment chez le vertébré les 


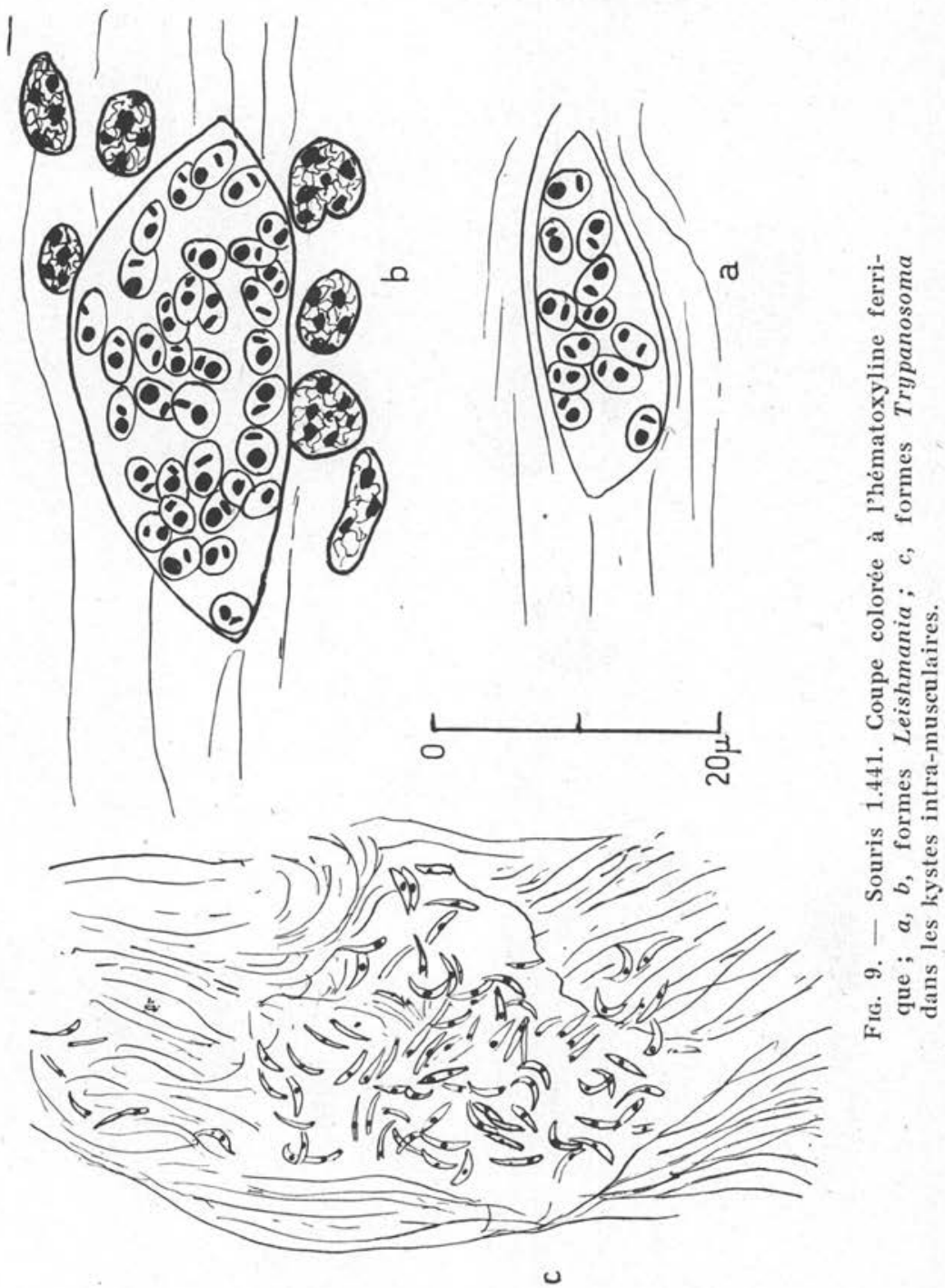

trypanosomes métacycliques se retransforment en formes Leishmania, comme Elkeles l'a vu dans les cultures. Wenyon avait émis l'idée que certaines formes Leishmania pourraient peut-être envahir le tissu sain et créer à leur tour un nouveau foyer. D'autre part, toutes les formes trouvées dans les frottis desséchés ont été considérées comme des formes de transition entre Leishmania et Trypanosoma, mais l'inverse n’a jamais été envisagé. 


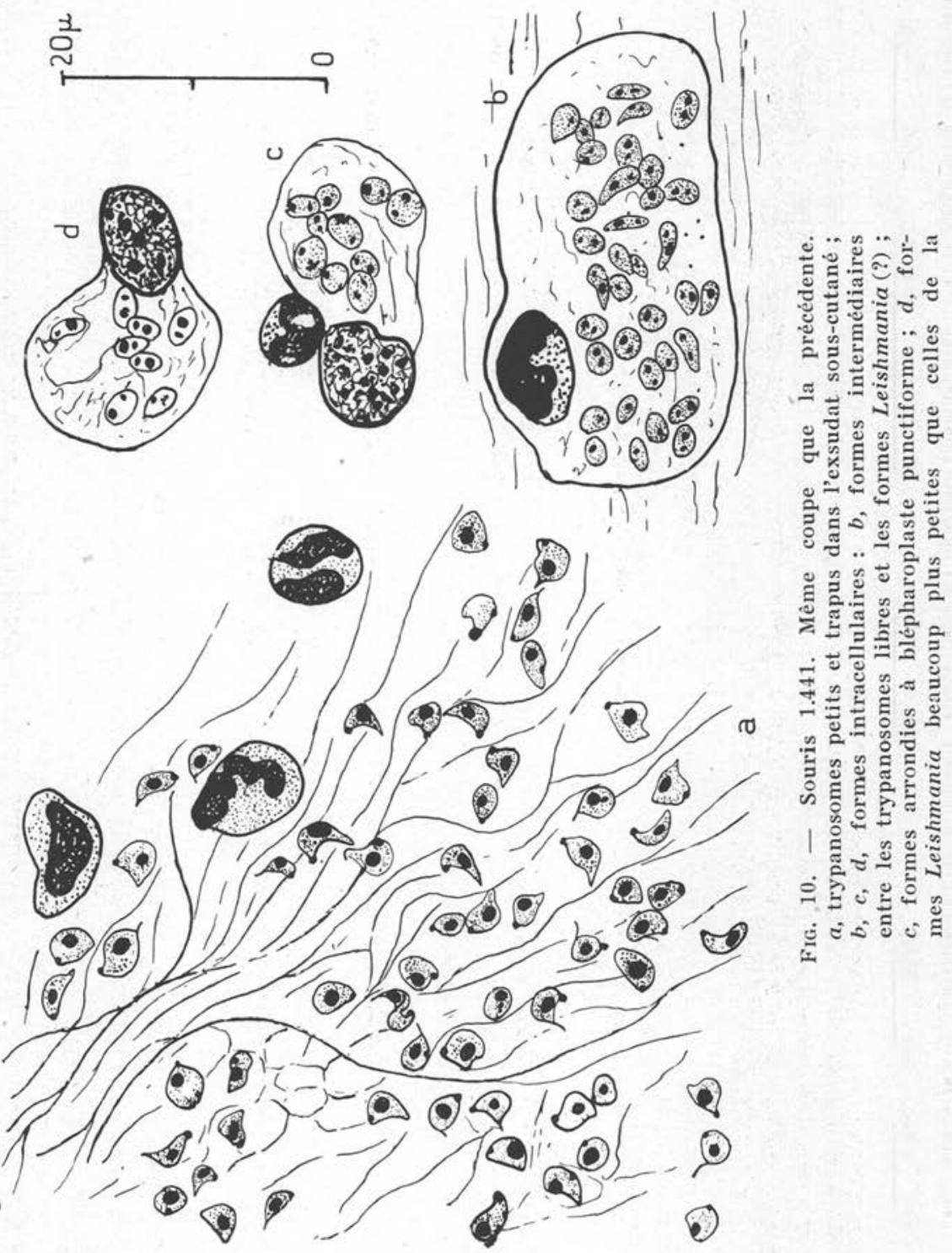

D'où deuxième hypothèse : il n'y a pas de raison pour que les formes libres que nous avons trouvées dans les coupes, et qui donnent l'aspect arrondi des frottis desséchés, ne soient pas des trypanosomes métacycliques en voie de transformation. Elles pénètrent 
dans les macrophages ou les cellules histiocytaires, et se transforment progressivement en Leishmania, et ce sont ces Leishmania qui à leur tour iraient former les kystes intramusculaires.

On pourrait nous objecter que ces formes n'ont été signalées que dans le cas particulier de nos expériences. Mais ce qui était facilement visible dans des infections intenses peut se produire aussi, bien que de façon moins évidente, dans des infections moyennes.

\section{Les trypanosomes métacycliques}

Il est fort probable que les trypanosomes si abondants dans le liquide péritonéal et parfois dans la sérosité sous-cutanée représentent exactement les formes que l'on trouve habituellement dans le sang. Ils ne viennent pas directement des kystes parasitaires à travers le péritoine, ils ne sont pas des formes de culture comme nous l'avons démontré par inoculation sous-cutanée.

On sait que le polymorphisme de $T$. cruzi dans le sang a été expliqué de façon différente. Pour Brumpt, Dias, F. D. Wood, les formes grêles et mobiles sont les formes jeunes, les formes larges et peu mobiles les plus âgées. Pour Chagas, il y aurait entre les deux formes une différenciation sexuelle.

D'autres, comme S. Wood, se basant sur l'existence possible de deux cycles, ont pensé que les formes Leishmania petites donneraient naissance aux trypanosomes grêles par développement direct, et les formes grandes, Leishmania de second ordre d'Elkeles, aux trypanosomes larges.

Nous avons représenté des formes trouvées dans le péritoine des souris à différents moments de leur infection. Comme nous l'avons dit, l'incubation, même après inoculation par voie sous-cutanée, était très courte, et nous avons pu trouver des trypanosomes dès les premiers jours, ce qui ne se produit jamais dans le sang.

La souris 1.359 (morte le $14^{\circ}$ jour avec un nombre incomptable de trypanosomes dans le péritoine et aucun dans le sang) a été examinée les $4^{\circ}, 5^{\circ}, 8^{\circ}, 13^{\circ}, 14^{\circ}$ jours (fig. 1 et 2 ). Chaque jour, le polymorphisme s'est manifesté, mais surtout dans les derniers jours où, à côté de formes très petites, on trouve des trypanosomes monstrueux (fig. 2, B). Le sang du cœur contenait aussi au moment de la mort des formes petites et grandes.

Dans le cas de la souris 1.441, on voit (fig. 6) que le pourcentage des formes courtes et des formes longues est également le même le $6^{\circ}$ jour et le $29^{\circ}$ jour, la veille de la mort. Il en est de même pour la goutte épaisse du sang périphérique (fig. $7, \mathrm{C}$ ) faite le lendemain. 


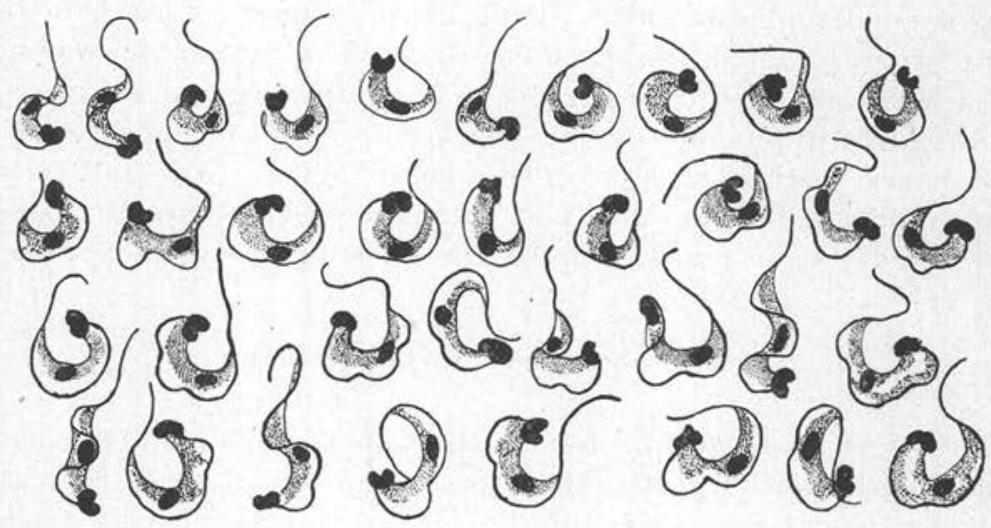

A
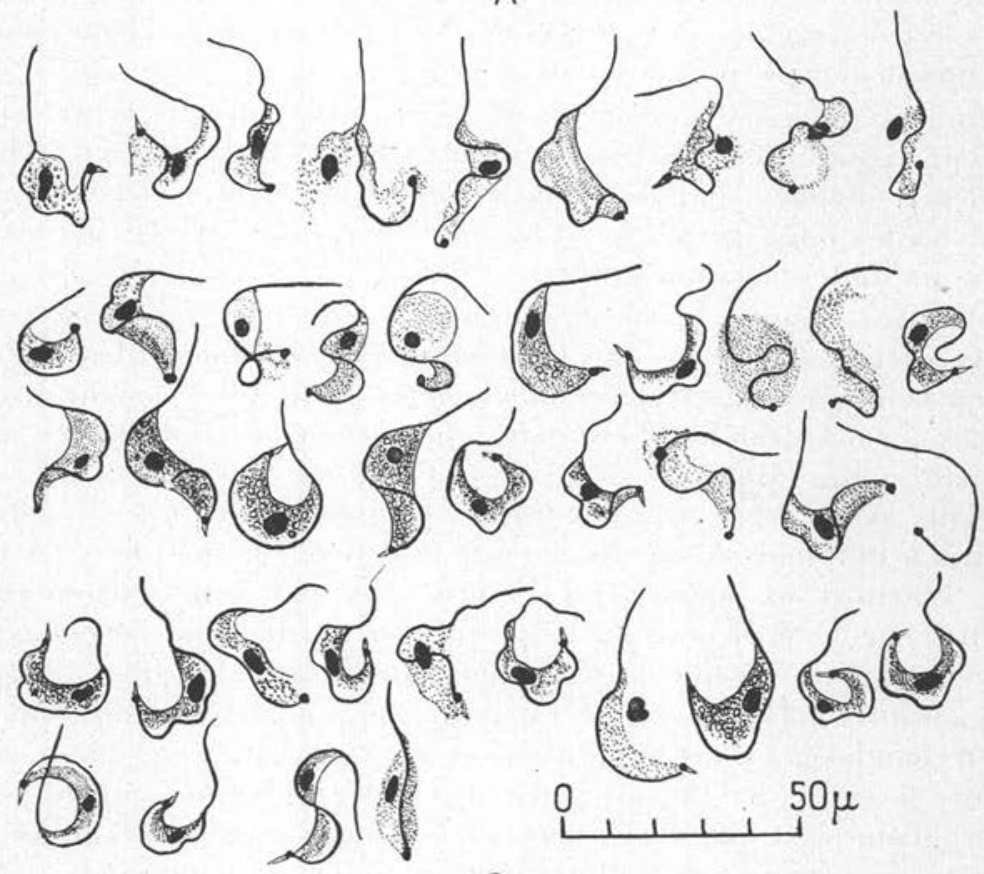

B

FIG. 11. - Trypanosoma vickersæ. A, goutte épaisse ; B, frottis: les trypanosomes ont été dessinés en partant de la queue vers l'origine de l'étalement.

On voit aussi que la ponction de l'exsudat sous-cutané peut retirer des trypanosomes comparables à ceux du péritoine (fig. 5, A), 
chez la souris 1.388 , ou des formes arrondies, comme dans le cas 1.441 (fig. 7, A), dont il a été question à propos des formes tissulaires. Le polymorphisme concerne surtout la longueur. On trouve tous les jours, jusqu'à la mort, une proportion entre les différentes formes qui est à peu près constante. Dans la sérosité péritonéale comme dans le sang, les trypanosomes se meuvent sur place à la période terminale, au lieu de traverser rapidement le champ du microscope. Ce phénomène, qui est en somme assez banal, concerne toutes les formes, et non pas seulement les formes minces.

Le polymorphisme n'est donc qu'apparent. Il est naturel que les formes courtes soient moins larges que les longues.

Les figures 3 et 4 montrent des préparations d'exsudat péritonéal de la souris 1.379 faites le $10^{\circ}$ jour et le $23^{\circ}$ jour. En A (fig. 3 et 4 ), on a fait un étalement épais ; en B (fig. 3 et 4), un frottis ordinaire mince. On voit que les formes larges et labiles ont été obtenues seulement dans les frottis minces. On y trouve parfois des zones entières où tous les trypanosomes sont détruits, sans qu'il soit possible d'en préciser la raison.

Ainsi, les formes sont plus ou moins larges, ou plus ou moins filiformes, suivant la méthode d'étalement et de fixation. Nous avons également représenté (fig. 11) $T$. vickersæ dans le sang périphérique de la souris en goutte épaisse (A) et dans un frottis (B). Les différences sont encore beaucoup plus marquées que dans l'exsudat péritonéal, où l'absence d'hématies permet la fixation directe des étalements épais et gouttes épaisses aussi bien que des frottis minces.

\section{Conclusions et Résumé}

Les difficultés de l'étude du cycle de Trypanosoma cruzi résident dans le fait qu'il se passe en partie dans les cellules ou dans l'intimité des tissus, et que les observations faites avec les cultures ou chez les arthropodes sensibles ne peuvent apporter aucun renseignement utile propre à élucider le problème. L'étude d'un matériel obtenu avec une souche de $T$. cruzi, ayant acquis spontanément la propriété de se multiplier principalement dans les muscles et le tissu conjonctif de la ceinture abdominale et des membres, avec localisation presque exclusive des formes flagellées dans le péritoine, le péricarde et l'œdème généralisé qui se produit souvent, nous a permis de faire les remarques suivantes:

La filiation des différentes formes de Leishmania à trypanosome, ou inversement, ne peut être étudiée que dans les coupes. En effet, dans les frottis par apposition ou par dilacération, on obtient : $1^{\circ}$ les

Ann. de Parasitologie, T. XXVII, No $1-2-3 .-1952$. 
formes contenues dans les kystes musculaires ; $2^{\circ}$ les formes sanguicoles ; $3^{\circ}$ des formes provenant de l'œdème ou contenues dans des cellules histiocytaires. L'établissement de la succession des différentes formes devient dans ces conditions un travail de pure imagination. On ne s'est pas étonné non plus que la multiplicité et le mélange de ces formes contrastaient avec le fait que les kystes intramusculaires ne contiennent chacun que des flagellés au même stade de leur évolution.

C'est gràce à cette méthode qu'on a pu décrire deux cycles évolutifs chez le vertébré, ce qui est difficile à concevoir et ne correspond pas à une nécessité biologique, à moins que l'on n'admette l'existence d'un processus sexué, ce que nous nous garderions bien de faire dans l'état actuel de nos connaissances.

L'étude de nos coupes montre, parfois dans un même champ : $1^{\circ}$ des formes intramusculaires : ou bien formes Leishmania, ou formes Leptomonas, ou des trypanosomes grêles et allongés ; $2^{\circ}$ des formes intracellulaires, dans les histiocytes ou les cellules endothéliales : des formes Leishmania normales, mais de petite taille, et des formes à blépharoplaste punctiforme arrondies ou allongées ; $3^{\circ}$ enfin, dans les mailles du tissu conjonctif ou dans l'œdème qui isole les faisceaux musculaires, des trypanosomes libres mais courts, trapus. Par ailleurs, nous avons pu voir dans de l'exsudat sous-cutané, obtenu par ponction, que ces trypanosomes, parfaitement mobiles à l'état frais, prenaient après fixation et coloration la forme arrondie qui, selon certains auteurs, constituerait une forme de transition entre les Leishmania et les trypanosomes (cycle indirect de S. Wood), bien qu'elle soit introuvable dans les kystes musculaires, mais qui est done en réalité un artifice de préparation concernant des trypanosomes déjà bien formés.

Il ne peut donc y avoir aucun rapport entre ces formes trapues, libres dans le tissu conjonctif, et les formes grêles trouvées dans les kystes musculaires parfois très voisins. Si c'était la coupe histologique seulement qui leur donnait cet aspect particulier, la fixation, après étalement, montrerait certainement des trypanosomes grêles et non des formes rondes.

Par contre, il y a certainement un rapport étroit entre ces formes trypanosomes libres et les formes arrondies ou ovalaires à blépharoplaste punctiforme trouvées dans les cellules histiocytaires : elles dérivent évidemment les unes des autres, mais dans quel sens ? Si nous écartons l'explication d'un vulgaire processus de phagocytose, qui est démenti par l'aspect histologique, il reste deux hypothèses :

$1^{\circ}$ Les formes Leishmania se trouvant dans les cellules histiocytaires seraient gênées dans leur multiplication et leur développement, et donneraient naissance à des trypanosomes arrondis pré- 
maturément libérés. Le processus serait d'origine purement mécanique, et nous reviendrions à admettre l'existence de deux cycles.

$2^{\circ}$ Les trypanosomes du sang périphérique, métacycliques, prendraient progressivement la forme arrondie en passant dans les mailles du tissu conjonctif, avant de pénétrer dans les histiocytes. Ils prendraient progressivement la forme Leishmania dans ces cellules qui les dissémineraient dans les organes, les muscles en particulier ici, exactement comme elles les disséminent à partir de la lésion initiale, dermique, ou chagome. Le cycle serait ainsi complété.

Il faut remarquer en effet que l'on n'a jamais envisagé chez le vertébré la complétion du cycle (et non la régression ou rétrogression, termes impropres et péjoratifs, puisque, après tout, c'est la forme Leishmania qui, se multipliant, est la forme noble), et que l'on n'a jamais décrit aucune forme trouvée dans les tissus pouvant être considérée comme une forme de transition entre la forme trypanosome et la forme Leishmania.

La précocité de l'apparition des formes trypanosomes dans l'exsudat péritonéal $\left(2^{\circ}\right.$ jour après inoculation sous la peau) et leur nombre déjà incomptable à la période moyenne de l'infection, les facilités de fixation et de coloration dans ce milieu sont particulièrement favorables à leur étude morphologique.

Nous avons constaté que le polymorphisme portait uniquement sur la longueur des trypanosomes. Les formes courtes et les formes longues sont en proportion constante depuis le début de l'infection jusqu'au jour de la mort. Ces formes se déplacent rapidement au début, elles restent sur place à la période avancée de l'infection, mais leur mobilité n'est aucunement en rapport avec leur morphologie. Elle dépend plutôt, probablement, des caractères physiques et antigéniques du sérum aux différents stades de la maladie.

Quant à l'existence des formes grêles du début de l'infection et des formes larges de la période d'état que les auteurs ont trouvées dans le sang, nous ne l'avons jamais observée dans le liquide ascitique, ni l'œdème sous-cutané, mais il est naturel que les formes courtes soient moins larges que les formes longues.

Par ailleurs, il paraît évident qu'une même forme peut être grêle ou large, résistante ou fragile, suivant la technique que l'on emploie.

\section{BIBLIOGRAPHIE}

Adie (Helen A.). - Preliminary note on the development of the LeishmanDonovan parasite in spleen juice and in the alimentary tract of Cimex lectularius. Indian J. Med. Res., IX, 1921; p. 225. 
Brumpt (E.). - Précis de Parasitologie, 1949, VI ${ }^{e}$ édition, Masson, éditeur, Paris.

Chagas (C.). - Nova tripanozomaze humana. Estudos sobre a morfoloja e o ciclo evolutivo de Schizotrypanum cruzi, ajerite etiologico de nova endidade morbida do homen. Mem. Inst. Oswaldo Cruz, I, 1909, p. 158-218.

Chatias (C.), Vit.lela (E.) et Da Rocha-Lima (H.). - Amerikanische Trypanosomenkrankheit. Mense's Handb. de Tropenkrankh., III, I, Vol. V, p. 673.

Chagas (E.). - Summula dos contrecimientos actuel sobre a Trypanosomiasis americana. Mem. Inst. Oswaldo Cruz, 1935, XXX, p. 387.

Dias (E.). - Estudos sobre o Schizotrypanum cruzi. Mem. Inst. Oswaldo Cruz, XXVIII, 1934, p. 1 .

Elketes (G.). - Investigaciones sobre la evolucion del Trypanosoma cruzi. Objeciones contra el concepto actual y fundamentos para un nuevo concepto sobre la eqolucion del Trypanosomas. Rev. Soc. Argent. Biol., XVI, 1940, p. 763.

- Investigaciones sobre el ciclo evolutivo del Trypanosoma cruzi. Nueva teoria sobre la evolucion de la forma tripanosomica. Nueva tecnica de fijacion humeda. La Sem. Méd., XXVII, 1940, p. 1.

- Investigaciones sobre la biologica del Trypanosoma cruzi. III' communicacion : El proceso de retrogresion de la forma tripanosomica. Rev. Soc. Argent. Biol., XVIII, 1942, p. 315.

- Enfermedad de Chagas ; consideraciones criticas acerca de los conceptos actualos sobre el mecanismo de su transmision al hombre y sobre el ciclo evolutivo de Trypanosoma cruzi. La Sem. Méd., XXIX, 1943, p. 178.

- Investigaciones sobre la evolucion del Trypanosoma cruzi, especialmente sobre la genesis de la forma tripanosomica. Bol. Acad. Nacional Cienc. Cordoba, XXXVI, 1944, p. 330.

- Experimental studies and critical considerations regarding the life cycle of Trypanosoma cruzi. Am. J. Trop. Med., XXV, 1945, p. 141.

Galciard (H.). - Remarques sur la eulture du Trypanosoma cruzi Chagas. Ann. Parasitol. Hum. Comp., VII, 1929, p. 367.

- Envahissement précoce et intense de la cavité abdominale chez la souris au cours des infections à Trypamosoma cruzi. Ann. Parasitol. Hum. Comp., VII, 1929 , p. 377 .

- Localisation péritonéale exclusive au cours de certaines infections à Trypanosoma cruzi chez la souris. Ann. Parasitol. Hum. Comp., VII, 1930, p. 140 .

Hartmann (M.). - Notiz über eine weitere Art der Schizogonie vom Schizotrypanum cruzi. Arch. f. Protistenk., XX, 1910, p. 276.

- Ueber die Schizogonie vom Schizotrypanum cruzi. Arch. f. Protistenk., XXXVIII, 1918, p. 113.

Hawking (F.). - Growth of protozoa in tissue culture. III. Trypanosoma cruzi. Trans. Royal Soc. Trop. Med. and Hyg., XL, 1946, p. 345.

Kofoid (C. A.) et Donat (F.). - South American Trypanosomiasis of the human type. Occurrence in mammals in the United States. Cal. West. Med., XXXVIII, 1933, p. 1.

KoFold (C. A.), Woon (F. D.) et MCNeIL (E.). - The cycle of Trypanosoma cruzi in tissue culture of embryonic heart muscle. Univ. Calif. Publ. Zool., XLI, 1935 , p. 23-24.

Longley (B. J.), Clausen (N. M.) et Tatum (A. L.). - Cultivation of various species of trypanosomes in developing chick embryo. Proc. Soc. Exp. Biol. Med., XLI, 1939, 23, p. 365-366. 
Manso Soto (A. E.), Lonetri (G. A.) et Rispoli (J. A.). - Cultivo de Trypanosoma cruzi en embrion de pollo. Mision Estud. Pat. Region. Argentine, XXI, 1950 , p. 23-32.

Mayer (M.) et Da Rocha-Lima (H.). - Zum Verhalten von Schizotrypanum cruzi in Warmblütern und Arthropoden. Arch. Schiff-Tropen-Hyg., XVIII, 1914, p. 101-136.

Mazza (S.) et Jorg (M. E.). - Consideraciones sobre la patogenia de la enfermedad de Chagas (los periodos anatomo-clinicos de la trypanosomiasis). Mendoza, 1935, 1-4 oct., 1, 221-236, 1936.

Mever (H.). - The cultivation of Protozoa in Tissue cultures. Monogr. Institute de Biofisica, Universidad do Brazil, 1949.

Meyer (H.) et de Oliverra (M. X.). - Cultivation of Trypanosoma cruzi in tissue cultures : a four-year study. Parasitology, XXXIX, 1948, (1/2), p. 91-94.

Minchin (E. A.) et Thosson (J. D.). - The rattrypanosome..... Quartely J. of Micr. Sci., XL, 1915, p. 463.

Muniz (J.). - Quelques formes intéressantes trouvées dans les cultures de Trypanosoma cruzi. C.R. Soc. Biol., XCVIII, 1927, p. 821.

MUnız (J.) et DE Freiras (G.). - Realização in vitro do ciclo do Schizotrypanum cruzi no vertebrado, em meios de caldo-liquido peritoneal. Rev. Brasil Biol., VI, 1946, p. 467.

Nıxo (F. L.). - Contribucion al estudio de la enfermedad de Chagas. Tesis Doctorado, Buenos-Aires, 1928.

Aspectos morfologicos del Schizotrypanum cruzi en los organismos de sus huespedes y en los medios de cultivo. Cuarta Reunion de la Soc. Argentina de Pat. regional del Norte Santiago del Estero, 7-9 mai 1928, p. 600.

Romaña (C.) et Meyer (H.). - Estudo do ciclo evolutivo do Schizotrypanum cruzi em cultura de tecidos de embrião de galinha. Memor. Inst. O. Cruz, XXXVII, 1942, p. 19.

Romagna (A.) et de Mondolfo (A. A.). - Papel del sistema linfatico en la propagacion del $S$. cruzi en la periodo inicial de la enfermedad de Chagas. An. del Inst. de Medic. regional (Tucuman), III, 1951, $\mathrm{n}^{\circ} 21$, p. 129.

Rovbaud (E.) et Romaña (C.). - Infection de l'embryon de poule par Schizotrypanum cruzi. Bull. Soc. Path. Exot., XXXIII, 1939, p. 874.

VIANNa (G.). - Contribução para o estudo de anatomia patologica da molestia de C. Chagas. Mem. Inst. Oswaldo Cruz, III, 1911, p. 276.

Wenyos (C. M.). - III Ed. Protozoology, Baillière, Tindall et Cox Londres, 1926, et William Wood \& $\mathrm{C}^{\circ}$, New-York.

Wood (F. D.). - Natural and experimental infection of Triatoma protracta. Uhler and mammals in California with American human trypanosomiasis. Am. J. Trop. Med., XIV, 1934, p. 497.

Wood (S. F.). - Additional observations on Trypanosoma cruzi Chagas from Arizona in insects, rodents, and experimentally infected animals. Am. Jour. Trop. Med., XXIX, 1949, p. 43.

Faculté de Médecine de Paris, Institut de Parasitologie. 